Grand Valley State University

ScholarWorks@GVSU

\title{
Enacted Support's Links to Negative Affect and Perceived Support are More Consistent with Theory when Social Influences are Isolated from Trait Influences
}

\author{
Brian Lakey \\ Grand Valley State University, lakeyb@gvsu.edu \\ Edward Orehek \\ University of Maryland \\ Kate L. Hain \\ Grand Valley State University \\ Meredith VanVleet \\ Grand Valley State University
}

Follow this and additional works at: https://scholarworks.gvsu.edu/psy_articles

Part of the Psychology Commons

\section{ScholarWorks Citation}

Lakey, Brian; Orehek, Edward; Hain, Kate L.; and VanVleet, Meredith, "Enacted Support's Links to Negative Affect and Perceived Support are More Consistent with Theory when Social Influences are Isolated from Trait Influences" (2010). Peer Reviewed Articles. 39.

https://scholarworks.gvsu.edu/psy_articles/39

This Article is brought to you for free and open access by the Psychology Department at ScholarWorks@GVSU. It has been accepted for inclusion in Peer Reviewed Articles by an authorized administrator of ScholarWorks@GVSU. For more information, please contact scholarworks@gvsu.edu. 


\title{
Enacted Support's Links to Negative Affect and Perceived Support Are More Consistent With Theory When Social Influences Are Isolated From Trait Influences
}

\author{
Brian Lakey,' Edward Orehek, ${ }^{2}$ Kate L. Hain,' \\ and Meredith VanVleet'
}

\begin{abstract}
Social support theory typically explains perceived support's link to mental health as reflecting the role of specific supportive actions (i.e., enacted support). Yet enacted support typically is not linked to mental health and perceived support as predicted by theory. The links are examined among enacted support, affect, and perceived support when links reflected (a) aspects of support and affect that generalized across relationship partners and time (i.e., trait influences) and (b) aspects that reflected specific relationship partners (i.e., social influences). Multivariate generalizability analyses indicated that enacted support was linked to low negative affect as predicted by theory only when correlations reflected social influences. When correlations reflected trait influences, enacted support was linked to high negative affect. Furthermore, perceived and enacted support were strongly linked when correlations reflected social influences but not trait influences. Thus, findings for enacted support fit social support theory better when social influences were isolated from trait influences.
\end{abstract}

\section{Keywords}

perceived support, enacted support, social support, affect

Received January 11, 2009; revision accepted June 24, 2009

Understanding social support's role in psychological wellbeing is an important goal for social psychology (Bolger \& Amarel, 2007; Campbell, Simpson, Boldry, \& Kashy, 2005; Collins \& Feeney, 2002; Gable, Reis, Impett, \& Asher, 2004; Lemay \& Clark, 2008). Perceptions that family and friends would provide effective help during times of stress (i.e., perceived support) have been consistently linked to good mental health, including low rates of major depression (Lakey \& Cronin, 2008), posttraumatic stress disorder (Brewin, Andrews, \& Valentine, 2000), eating disorders (Stice, 2002), low psychological distress (Barrera, 1986; Cohen \& Wills, 1985), and low negative as well as high positive affect (Finch, 1998).

The dominant stress and coping social support theory explains the link between perceived support and mental health as reflecting the specific supportive actions provided by family and friends during stressful circumstances (i.e., enacted support; e.g., advice, reassurance; Cutrona \& Russell, 1990; Thoits, 1986). Stress increases risk for psychological distress and disorder, and there are important individual differences in the extent to which stress increases risk (i.e., stress buffering; e.g., Cohen \& Wills, 1985). One important determinant of stress buffering is effective coping.
Enacted support promotes effective coping, when it matches the demands of the stressor (Cohen \& Hoberman, 1983; Cutrona \& Russell, 1990). Perceived support reflects a person's history of receiving effective enacted support.

Yet enacted support has not shown the predicted pattern of correlations with other constructs. There are two chief problems. First, receiving enacted support has not been consistently linked to better mental health (Barrera, 1986), with one metaanalysis estimating the link at $r=.12$ (Finch, Okun, Pool, \& Ruehlman, 1999). This is in contrast to perceived support's link of about $r=.32$; a tenfold difference in proportion of variance explained. Moreover, several studies have found that receiving enacted support was linked to worse instead of better mental health (Barrera, 1986; Bolger \& Amarel, 2007; Bolger, Zuckerman, \& Kessler, 2000; Gleason, Iida, Shrout,

\footnotetext{
'Grand Valley State University

${ }^{2}$ University of Maryland

Corresponding author:

Brian Lakey, Department of Psychology, Grand Valley State University, Allendale, MI 4940I

Email: lakeyb@gvsu.edu
} 
\& Bolger, 2008). Second, enacted support has not been as strongly linked to perceived support as implied by theory (Barrera, 1986). Haber, Cohen, Lucas, and Baltes's (2007) meta-analysis estimated the link at $r=.35$. Although a link accounting for $12 \%$ of the variance is not trivial, many investigators have interpreted stress and coping theory to predict a much stronger link (Lakey \& Cohen, 2000).

The weak and countertheoretical links between enacted support and mental health as well as the comparatively weak links between perceived and enacted support present a serious challenge to stress and coping social support theory as the theory explains the well-replicated link between perceived support and mental health as resulting from enacted support. Enacted support cannot be the explanation if enacted support itself is not linked to better mental health and if enacted and perceived support are not closely linked.

Given the importance of enacted support to social support theory, there have been surprisingly few published attempts to explain enacted support's unexpected pattern of findings. Barrera (1986) hypothesized that enacted support might be weakly linked to mental health because stress leads providers to give increased enacted support to recipients, but stress also worsens recipients' mental health. Yet Seidman, Shrout, and Bolger (2006) showed in simulations that this explanation required implausibly large correlations. Finch et al. (1997) examined enacted support subtypes and found that positive social exchange displayed weak correlations with subclinical depression in the direction predicted by theory. Yet the authors did not test whether this subtype could explain perceived support's link to low depression. Rini, Dunkel Schetter, Hobel, Glynn, and Sandman (2006) found that enacted support acted more as predicted by theory when the authors assessed participants' subjective judgments of enacted support quality. Yet assessing participants' subjective judgments of enacted support might have converted their measure of enacted support into a measure of perceived support. Finally, in an especially promising approach, Gleason et al. (2008) found that enacted support was linked to better mental health only among participants who experienced increases in closeness to their partners in response to enacted support.

In the present research, we addressed enacted support's unexpected links to affect and perceived support by using Cronbach and colleagues' multivariate generalizability $(G)$ theory (Brennan, 2001a; Cronbach, Gleser, Nanda, \& Rajaratnam, 1972; Strube, 2000), which can isolate the traitlike and socially influenced aspects of support and affect. Although most widely known for its theory of reliability, G theory is essentially similar to the social relations model (SRM; Kenny, 1994) in that both can partition variance into the same sources. As applied to person perception, the SRM typically partitions variance into perceiver, target, and relational influences when perceivers rate the same targets. As applied to social support specifically, variance is partitioned into support recipient, support provider, and relational influences. Recipient trait influences reflect differences among recipients in their ratings of providers, averaged across providers and (ideally) time. For example, Recipient A might consistently rate both Providers A and B as more supportive than does Recipient B. Provider influences reflect interrater agreement among recipients about providers' relative supportiveness. For example, Provider A might be seen as more supportive by both Recipients A and B than is Provider B. Relational influences reflect systematic disagreements among recipients in their ratings of providers and, as such, reflect the aspect of supportiveness that reflects personal taste. For example, Recipient A might rate Provider A as more supportive than Provider B, but Recipient B might have the opposite opinion. A recent meta-analysis of three American studies and two European studies indicated that relational influences accounted for approximately $65 \%$ of the variance in perceived support, recipient influences accounted for approximately $25 \%$, and provider influences accounted for less than 10\% (Lakey, in press).

The findings just described were based on fully crossed designs in which recipients rated the same providers. For the present studies, we used a variation of this design in which recipients rated their mothers, fathers, and most important peers. Thus, providers were nested within recipients, as each recipient had different mothers, fathers, and peers. The advantage of the nested design is that recipients rated some of the most important people in their lives, which is sometimes difficult to achieve in the fully crossed design. The disadvantage is that the nested design confounds relational and provider influences in a single social influences component.

Once recipient trait and social influences have been isolated, multivariate G analyses (Cronbach et al., 1972) permit investigators to estimate correlations among constructs for each influence separately. This is important because the same construct can have different patterns of correlations when the correlations reflect different variance components (Eastwick, Finkel, Mochon, \& Ariely, 2008; Kwan, John, Kenny, Bond, $\&$ Robins, 2004). For example, Lakey and Scoboria (2005) found that positive and negative affect were mostly independent when correlations reflected trait influences but were moderately negatively correlated when the constructs reflected social influences. Barry, Lakey, and Orehek (2007) and Merlo and Lakey (2007) found that attachment avoidance was related to worse mental health only when correlations reflected social influences but not when correlations reflected trait influences. Especially relevant to the current article is Merlo and Lakey's findings regarding support seeking. Support seeking has yielded findings similar to enacted support in that support seeking's link to mental health has been much smaller than implied by theory (Penley, Tomaka, \& Wiebe, 2002). Merlo and Lakey found that support seeking was composed of approximately equal parts trait and social influences. Support seeking was unrelated to mental health when the 
correlation reflected trait influences. Yet when the correlation reflected social influences, support seeking was linked to mental health as expected.

Merlo and Lakey's (2007) findings for support seeking suggest a potential explanation for enacted support's countertheoretical links to psychological distress and perceived support. Lemay and Clark (2008; Study 5) recently reported that enacted support reflected both trait and social influences. Perhaps the trait influences account for enacted support's unexpected pattern of findings. When correlations reflect recipient traits, enacted support might be only weakly linked to perceived support and unrelated to mental health. Yet when correlations reflect social influences, enacted support might act as predicted by theory with links to mental health as well as strong links to perceived support. The current studies tested these predictions. In addition, when enacted support behaved according to theory, we examined whether controlling for enacted support could account for perceived support's link to mental health, as predicted by stress and coping social support theory.

\section{Study I}

\section{Method}

Participants. Three hundred and twelve students $(66 \%$ female; $82 \%$ European ancestry) at a regional state university in Western Michigan participated as part of a course requirement. The vast majority of participants were firstsemester freshmen (average age $=18.7$ ). College students were appropriate for this research because (a) the phenomena under investigation have been well established in this population and (b) enacted support (especially from parents) might be especially useful for first-semester freshmen.

Procedure. Participants completed each measure separately for three support providers: mothers (or mother figures), fathers (or father figures), and closest peers. Most participants rated their biological mothers $(93 \%)$ and biological fathers $(86 \%)$. For peer ratings, most participants rated best friends $(72 \%)$ compared to romantic partners (28\%). Participants typically had contact with providers at least several times a week $(83 \%$ of mothers, $61 \%$ of fathers, and $86 \%$ of closest peers). Sixty percent of relationships with closest peers had lasted 1 year or more, whereas only $4 \%$ had lasted 2 months or less. The order in which participants rated mothers, fathers, and peers was counterbalanced. To minimize order effects, measures were presented in one of five different orders for each provider.

\section{Measures}

Enacted support. Participants rated the support received from each provider using Barrera, Sandler, and Ramsay's (1981) Inventory of Socially Supportive Behaviors (ISSB). The measure is widely regarded as a measure of enacted support (Wills \& Shinar, 2000), and it yields the weak links to perceived support and mental health that are problematic for stress and coping social support theory (Barrera, 1986; Finch et al., 1999; Haber et al., 2007). The ISSB is composed of 40 items that refer to relatively specific supportive actions provided during the past month. Response options range from not at all to about every day. The ISSB is composed of four factor-analytically derived subscales: directive guidance (e.g., "suggested some action you should take"), nondirective support (e.g., "expressed interest and concern in your well-being"), positive social exchange (e.g., "talked with you about some interests of yours"), and tangible assistance (e.g., "provided you with transportation"). In the current sample, internal consistency reliability ${ }^{1}$ was 1.00 for trait influences and .95 for social influences.

Affect. Participants rated the affect typically experienced when with each relationship figure using the Positive and Negative Affectivity Schedule (PANAS; Watson, Clark, \& Tellegen, 1988). Measures of affect specific to each relationship figure were required to estimate correlations for social influences specifically. We used the PANAS because (a) positive affect and negative affect have been identified as important constituents of the affective component of mental health and disorders, including DSM disorders such as major depression and anxiety disorders (Watson, Clark, \& Carey, 1988); (b) the scales have been used successfully for assessing both trait and state affect (Watson, Clark, \& Tellegen, 1988); and (c) the scales have been useful in our team's previous studies of social support using multivariate G techniques (Barry et al., 2007; Lakey \& Scoboria, 2005). In addition, it is important to assess both positive and negative affect in studies of social support, as some research has found stronger links between support and positive affect than between support and negative affect (Finch, 1998). Example items included "enthusiastic" and "interested" for positive affect and "nervous" and "upset" for negative affect. For positive affect, internal consistency reliability was .95 for trait influences and .89 for social influences. For negative affect, internal consistency reliability was .95 for trait influences and .88 for social influences.

Perceived support. Participants rated the supportiveness of each provider using the seven-item perceived support subscale from the Quality of Relationships Inventory (QRI; Pierce, Sarason, \& Sarason, 1991). The perceived support items from the QRI have substantial evidence for their reliability and validity and have been used successfully in previous multivariate $\mathrm{G}$ studies of social support. Example items included "To what extent can you count on your mother to listen to you when you are very angry at someone else?" and "To what extent can you turn to your mother for advice about problems?" Internal consistency reliability was .93 for trait influences and .90 for social influences.

Statistical analyses. Estimates of the strength of trait and social influences for each construct were derived from the 
VARCOMP procedure within SPSS (Version 14.0). Data were analyzed as providers nested within Recipients $\times$ Items ANOVAs using restricted maximum likelihood estimation with random factors. This is an example of a "one perceiver, many targets design" (1PMT) described by Kenny and Winquist (2001). Recipients were a between-subjects factor; providers and items were within-subjects factors. Each participant was a level of the recipients factor, each provider was a level of the providers factor, and each of the two aggregates of odd and even items was a level of the items factor. The providers factor was nested within the recipients factor, and therefore provider and relational effects were combined into a single social influences effect. Items were fully crossed with both providers and recipients. Following our team's prior studies (Barry et al., 2007; Lakey \& Scoboria, 2005; Merlo \& Lakey, 2007), odd and even items were summed to reduce measurement error and to simplify the design. The design yielded five effects: recipients (i.e., recipient trait influences), providers nested with recipients (i.e., social influences), items, Recipients $\times$ Items, and providers nested within Recipients $\times$ Items. As there was only one observation per cell, the highest order interaction (providers nested within Recipients $\times$ Items) was used as the error term (Kenny, 1994). We report only the effects of recipients (i.e., trait influences) and providers nested within recipients (i.e., social influences) as the other effects are not relevant to the questions addressed in the present article. Nonetheless, in reporting proportion of variance explained (e.g., see Tables 1 and 3 later in this article), variances from all effects were used to calculate total variance. The results for effects not reported here are available from the authors.

Multivariate G analyses (Brennan, 2001a; Cronbach et al., 1972; Strube, 2000) were used to estimate correlations among constructs for recipient trait and social influences specifically, using the computer program Mgenova (Brennan, 2001b). As there are no parametric significance tests for multivariate $\mathrm{G}$ correlations, we estimated standard errors through normal approximation bootstrapping (Mooney \& Duval, 1993). Bootstrapping takes multiple random resamples (with replacement) from the study data and estimates sampling error from the standard deviation of the bootstrapestimated sampling distribution (i.e., the standard error). As in our team's previous work (Barry et al., 2007; Lakey \& Scoboria, 2005; Merlo \& Lakey, 2007; Neely et al., 2006), we based estimates on 50 resamples using Stata (Stata Corp, 2003) because 50 provides adequate estimates (Mooney \& Duval, 1993) and because 50 was a practical necessity given that Mgenova required manual bootstrapping. In normal approximation bootstrapping, 95\% confidence intervals are established by taking the $z$ values that demarcate the upper and lower $2.5 \%$ of the distribution and multiplying the $z$ values by the standard error.

Some of our research questions required comparing the magnitude of two correlations (e.g., Was enacted support linked to negative affect differently when correlations reflected trait versus social influences?). The standard errors for differences were estimated by subtracting one correlation (e.g., trait influences) from the second correlation (e.g., social influences) for each of the 50 resamples and then taking the standard deviation of the estimated sampling distribution of the differences (i.e., the standard error).

\section{Results and Discussion}

We first report the strength of trait and social influences for each construct as well as whether the two influences differed significantly (determined by whether their $95 \%$ confidence intervals overlapped). As displayed in Table 1, each construct had significant trait and social influences. Consistent with previous research (Lakey \& Scoboria, 2005), perceived support was composed of significantly more social than trait influences, whereas positive affect and negative affect were composed of approximately equal portions of trait and social influences. In contrast to perceived support, enacted support was composed equally of trait and social influences. ${ }^{2}$

Next, we examined whether enacted support had different links to affect and perceived support when the links reflected trait or social influences. As described momentarily, results revealed that enacted support had countertheoretical links to negative affect and perceived support when links reflected trait influences. In contrast, enacted support's links to negative affect and perceived support were much more consistent with stress and coping social support theory when correlations reflected social influences. Links between enacted support and positive affect were unaffected by whether trait or social influences were examined.

When correlations reflected trait influences (Table 2), the recipients who characteristically received more enacted support also characteristically experienced more negative affect. Yet this correlation was reversed when it reflected social influences, and recipients experienced less negative affect in dyads when providers gave more enacted support. The difference between the correlations was statistically significant $\left(\Delta \rho=.58 ; S E_{\Delta}=.11\right)$.

Consistent with the findings for negative affect, enacted support's weak link to perceived support was observed only when correlations reflected trait influences (Table 2). When correlations reflected social influences, enacted support was strongly linked to perceived support, as predicted by stress and coping social support theory. For social influences, the providers that gave more enacted support were perceived as more supportive. Perceived and enacted support were also linked when correlations reflected trait influences, such that the recipients who characteristically received enacted support also characteristically perceived providers as supportive. Yet the link between perceived and enacted support was significantly stronger when the link reflected social influences compared to trait influences $\left(\Delta \rho=.26 ; S E_{\Delta}=.13\right)$. 
Table I. Recipient Trait and Social Influences in Study I

\begin{tabular}{|c|c|c|c|c|}
\hline Source & Variance component & Standard error & $95 \%$ confidence interval & Proportion of variance \\
\hline \multicolumn{5}{|l|}{ Perceived support } \\
\hline Recipient trait influences & .10 & .02 & $.06-.14$ & $.19 *$ \\
\hline Social influences & .34 & .02 & $.30-.38$ & $.63 *$ \\
\hline \multicolumn{5}{|l|}{ Positive affect } \\
\hline Recipient trait influences & .27 & .04 & $.20-.34$ & $.36^{*}$ \\
\hline Social influences & .36 & .02 & $.31-.40$ & $.47^{*}$ \\
\hline \multicolumn{5}{|l|}{ Negative Affect } \\
\hline Recipient trait influences & .12 & .02 & $.08-.15$ & $.35^{*}$ \\
\hline Social influences & .16 & .01 & $.14-.18$ & $.48^{*}$ \\
\hline \multicolumn{5}{|l|}{ Enacted support } \\
\hline Recipient trait influences & .32 & .04 & $.25-.39$ & $.46^{*}$ \\
\hline Social influences & .33 & .02 & $.29-.36$ & $.47^{*}$ \\
\hline
\end{tabular}

$*_{p}<.05$

Table 2. Multivariate Generalizability Correlations $(\rho)$ and (Standard Errors) for Study I

\begin{tabular}{|c|c|c|c|c|}
\hline Variable & Enacted support & Negative affect & Perceived support & Positive affect \\
\hline \multicolumn{5}{|l|}{ Enacted support } \\
\hline Trait influences & - & $.30 *(.08)$ & $.37 *(.11)$ & $.5 \mathrm{I} *(.06)$ \\
\hline Social influences & - & $-.28 *(.06)$ & $.63 *(.03)$ & $.47 *(.04)$ \\
\hline \multicolumn{5}{|l|}{ Negative affect } \\
\hline Trait influences & & - & $-.31 *(.10)$ & $.07(.08)$ \\
\hline Social influences & & - & $-.42 *(.05)$ & $-.4 I^{*}(.04)$ \\
\hline \multicolumn{5}{|l|}{ Perceived support } \\
\hline Trait influences & & & - & $.38 *(.08)$ \\
\hline Social influences & & & - & $.64 *(.03)$ \\
\hline \multicolumn{5}{|l|}{ Positive affect } \\
\hline Trait influences & & & & - \\
\hline Social influences & & & & - \\
\hline
\end{tabular}

$*_{p}<.05$.

Although the links between perceived and enacted support were significantly different when the links reflected trait versus social influences in the current study, how do our estimates compare with what is typically found? To examine this, we compared our estimates against Haber et al.'s (2007) reliability-corrected, meta-analytic estimate of $r=.35(95 \%$ confidence interval $[\mathrm{CI}]=.32$ to .39$)$. When the correlation reflected social influences, there was a significantly stronger link between perceived and enacted support in the current study than estimated by Haber et al. The lower bounds of the $95 \%$ CIs for the current study (.60 to .66) greatly exceeded the upper bounds of Haber et al.'s estimate. In contrast, the link between perceived support and enacted support for trait influences was not significantly different from Haber et al.'s estimate, as the $95 \%$ CIs for the current study (.15 to .59) overlapped with Haber et al.'s CIs.

Enacted support was strongly and significantly linked to positive affect regardless of whether correlations reflected trait or social influences (Table 2). Recipients who characteristically received more enacted support also characteristically experienced more positive affect, and recipients experienced more positive affect in dyads when providers gave more enacted support. The difference between the correlations was small and not significant $\left(\Delta \rho=.04 ; S E_{\Delta}=.08\right)$.

Finally, we tested the extent to which enacted support could account for perceived support's link to affect. Stress and coping social support theory hypothesizes that the link between perceived support and affect reflects the receipt of enacted support. If so, statistically controlling for enacted support should eliminate correlations between perceived support and affect. For these analyses, we used the SPSS (Version 14.0) multiple regression routine to remove enacted support's variance from perceived support, positive affect, and negative affect, yielding standardized residuals for the three variables. ${ }^{3}$ We then calculated multivariate $G$ analyses as described previously.

When correlations reflected social influences and enacted support was controlled, perceived support's link to low 
negative affect was significantly reduced $\left(\Delta \rho=.05 ; S E_{\Delta}=\right.$ $.02)$. Nonetheless, the magnitude of the reduction was quite small, and perceived support remained significantly and substantially correlated with low negative affect $(\rho=-.37 ; S E=$ .04). Similarly, controlling for enacted support significantly reduced the magnitude of the correlation between perceived support and positive affect $\left(\Delta \rho=.15 ; S E_{\Delta}=.02\right)$ when correlations reflected social influences. Yet the correlation between perceived support and positive affect remained strong and significant when enacted support was controlled $(\rho=.49 ; S E=.03)$. Thus, although enacted support could explain portions of the links between perceived support and low negative and high positive affect, these portions were rather small.

Stress and coping social support theory does not make predictions regarding the extent to which enacted support can explain perceived support's link to affect when correlations reflect trait influences. Nonetheless, controlling for enacted support sheds some light on the trait-like aspect of perceived support. Controlling for enacted support significantly increased the link between perceived support and low negative affect $\left(\Delta \rho=.24 ; S E_{\Delta}=.06\right)$ and so, of course, perceived support remained significantly correlated with low negative affect $(\rho=-.55 ; S E=.07)$ when correlations reflected trait influences. Thus, enacted support suppressed the link between perceived support and low negative affect when correlations reflected trait influences. In contrast, the correlation between perceived support and positive affect was significantly reduced when enacted support was controlled $\left(\Delta \rho=.15 ; S E_{\Delta}=.07\right)$ but remained statistically significant $(\rho=.23 ; S E=.09)$.

In summary, the results from Study 1 suggest that enacted support might have shown countertheoretical links to negative affect and perceived support in previous studies because the studies did not isolate trait from social influences. Yet an important limitation of Study 1 is that participants completed measures in a single session. This is important because our use of the term trait and social influences implies that these influences are durable over time. Yet other research has revealed that some of the variance assigned to trait and social influences (when assessment is based on a single occasion) reflects day-to-day changes in support and affect instead (Neely et al., 2006). The solution to this potential imprecision is to assess recipients at more than one point in time and to average out effects unique to single time points (Neely et al., 2006).

\section{Study 2}

The goals of Study 2 were to replicate Study 1 at a different university in a different part of the country and to assess recipients at two time points so that trait and social influences could be estimated while averaging out the effects of transient affect and transient relationship perceptions. Thus, recipients completed the same measures as in Study 1 twice separated by 2 weeks. Analyses were based on responses averaged across the two time points. Although two assessment points might remind readers of the prospective design common in social support research (e.g., Finch, 1998), our goal was not to use Time 1 support measures to forecast changes in affect over time. ${ }^{4}$

\section{Method}

Participants. One hundred and one students (55\% female; $64 \%$ European ancestry) participated in exchange for course credit. Participants were enrolled in an upper-level, general education psychology course at a large, public research university in a Mid-Atlantic, urban area. The average age was 20.9 years.

Procedure and Measures. The procedure and measures for Study 2 were identical to Study 1 except that participants in Study 2 completed the measures on two occasions separated by 2 weeks. For all analyses, participants' responses were averaged across the two time points. Ninety-four percent of the participants who completed the measures at Time 1 completed measures at Time 2 .

Ninety-five percent of participants rated biological mothers and $91 \%$ rated biological fathers. Sixty percent of peers were best friends and $40 \%$ were romantic partners. Most participants reported contact with their mothers $(82 \%)$ and fathers $(63 \%)$ at least several times per week. Ninety-one percent of participants reported contact with their most important peers at least several times per week. Eighty-six percent of participants had known their peers for 1 year or more.

Internal consistency reliabilities for trait and social influences, respectively, were .97 and .89 for perceived support, .98 and .89 for negative affect, .98 and .85 for positive affect, and .99 and .97 for enacted support.

\section{Results and Discussion}

Study 2 substantially replicated the findings of Study 1 . As displayed in Table 3, each construct had significant trait and social influences. Perceived support was composed of significantly more social than trait influences, whereas positive affect, negative affect, and enacted support were approximately equally composed of trait and social influences.

Recipients who characteristically received more enacted support also characteristically experienced more negative affect when correlations reflected trait influences (Table 4). Yet the link between enacted support and negative affect was reversed when correlations reflected social influences. Recipients experienced less negative affect in dyads in which providers gave more enacted support. The difference between these correlations was statistically significant $\left(\Delta \rho=.67 ; S E_{\Delta}=.20\right)$.

Perceived support was strongly and significantly linked to receiving more enacted support when correlations reflected 
Table 3. Recipient Trait and Social Influences in Study 2

\begin{tabular}{|c|c|c|c|c|}
\hline Source & Variance component & Standard error & $95 \%$ confidence interval & Proportion of variance \\
\hline \multicolumn{5}{|l|}{ Perceived support } \\
\hline Recipient trait influences & .08 & .02 & $.03-.13$ & $.23 *$ \\
\hline Social influences & .21 & .02 & $.16-.25$ & $.59 *$ \\
\hline \multicolumn{5}{|l|}{ Positive affect } \\
\hline Recipient trait influences & .28 & .05 & $.18-.39$ & $.51 *$ \\
\hline Social influences & .19 & .02 & $.14-.23$ & $.33 *$ \\
\hline \multicolumn{5}{|l|}{ Negative affect } \\
\hline Recipient trait influences & .09 & .02 & $.05-.13$ & $.39 *$ \\
\hline Social influences & .11 & .01 & $.09-.14$ & $.47 *$ \\
\hline \multicolumn{5}{|l|}{ Enacted support } \\
\hline Recipient trait influences & .22 & .05 & $.13-.32$ & $.42 *$ \\
\hline Social influences & .29 & .03 & $.23-.34$ & $.53 *$ \\
\hline
\end{tabular}

$*_{p}<.05$.

Table 4. Multivariate Generalizability Correlations $(\rho)$ and (Standard Errors) for Study 2

\begin{tabular}{|c|c|c|c|c|}
\hline Variable & Enacted support & Negative affect & Perceived support & Positive affect \\
\hline \multicolumn{5}{|l|}{ Enacted support } \\
\hline Trait influences & - & $.44^{*}(.17)$ & $.31(.17)$ & $.53 *(.11)$ \\
\hline Social influences & - & $-.23 *(.07)$ & $.62 *(.05)$ & $.58 *(.07)$ \\
\hline \multicolumn{5}{|l|}{ Negative affect } \\
\hline Trait influences & & - & $-.28(.19)$ & $.16(.19)$ \\
\hline Social influences & & - & $-.36 *(.08)$ & $-.44 *(.07)$ \\
\hline \multicolumn{5}{|l|}{ Perceived support } \\
\hline Trait influences & & & - & $.58 *(.13)$ \\
\hline Social influences & & & - & $.57 *(.06)$ \\
\hline \multicolumn{5}{|l|}{ Positive affect } \\
\hline Trait influences & & & & - \\
\hline Social influences & & & & - \\
\hline
\end{tabular}

$*_{p}<.05$.

social influences such that providers who gave more enacted support were perceived as more supportive. In contrast, there was no significant link between perceived and enacted support when correlations reflected trait influences. Even though the difference in magnitudes of the correlations was large (.31) and nearly identical to the differences observed in Study 1 (.26), the difference between trait and social influences was not statistically significant $\left(S E_{\Delta}=.20 ; p<.12\right)$. Nonetheless, when the correlation reflected social influences, perceived and enacted support were significantly more strongly linked $(95 \% \mathrm{CI}=.52$ to .73$)$ than in Haber et al.'s (2007) meta-analytic estimate of $r=.35(95 \% \mathrm{CI}=.32$ to .39). In contrast, the link between perceived support and enacted support for trait influences $(95 \% \mathrm{CI}=-.01$ to .65$)$ was not significantly different from Haber et al.'s estimate.

Regardless of whether correlations reflected recipient trait or social influences, enacted support was linked strongly and significantly to positive affect (Table 4). That is, recipients who characteristically received more enacted support also characteristically experienced more positive affect and recipients experienced more positive affect in dyads in which providers gave more enacted support. The difference between trait and social influence correlations was small and not significant $\left(\Delta \rho=.05 ; S E_{\Delta}=.15\right)$.

Finally, we tested the extent to which enacted support could account for perceived support's link to positive affect and low negative affect for social influences, as predicted by stress and coping social support theory. We calculated multivariate $\mathrm{G}$ analyses controlling for enacted support according to the procedures used in Study 1.

For social influences, when enacted support was removed, perceived support's link to low negative affect was not significantly reduced $\left(\Delta \rho=.01 ; S E_{\Delta}=.05\right)$ and perceived support remained significantly correlated with low negative affect $(\rho=-.35 ; S E=.08)$. In contrast, controlling for enacted support significantly and substantially reduced the magnitude of the correlation between perceived support and positive affect for social influences $\left(\Delta \rho=.37 ; S E_{\Delta}=.05\right)$. Yet the correlation between perceived support and positive affect remained significant $(\rho=.20 ; S E=.07)$. 
For trait influences, controlling for enacted support significantly increased the link between perceived support and low negative affect when correlations reflected trait influences $\left(\Delta \rho=.26 ; S E_{\Delta}=.13\right)$. When enacted support was removed, perceived support was strongly and significantly linked to low negative affect $(\rho=-.54 ; S E=.11)$. That is, recipients who characteristically perceived providers as more supportive characteristically experienced less negative affect. Thus, enacted support suppressed the correlation between perceived support and low negative affect when correlations reflected trait influences. Controlling for enacted support did not significantly reduce the link between perceived support and positive affect $\left(\Delta \rho=.10 ; S E_{\Delta}=.08\right)$ for trait influences and the correlation between perceived support and positive affect remained significant when enacted support was controlled $(\rho=.48 ; S E=.13)$.

In summary, Study 2 substantially replicated the findings in Study 1 using a design that minimized the potential influences of transient affect and transient perceptions and using a sample from a different part of the United States. In both studies, when correlations reflected trait influences, enacted support behaved in a way contrary to stress and coping social support theory: Receiving enacted support was linked to more negative affect and was only modestly (Study 1) or nonsignificantly (Study 2) linked to perceived support. In contrast, when correlations reflected social influences, enacted support behaved more consistently with stress and coping social support theory: Enacted support was linked to less negative affect and was strongly linked to perceived support. Yet enacted support could only partially explain perceived support's link to favorable affect. Perceived support was significantly and strongly linked to both positive and low negative affect when enacted support was controlled. In contrast to negative affect, enacted support's link to positive affect did not depend on whether trait or social influences were analyzed. This indicates that there was nothing in the study design or analyses that guaranteed different pattern of findings for trait and social influences.

\section{General Discussion}

Pending replication by other investigators, we believe we have partially explained why enacted support has not behaved as predicted by stress and coping social support theory. The standard methods in social support research have not isolated trait and social influences, and thus estimates of the link between social support and other constructs likely have confounded these two influences. Such confounding likely has led to misleading findings for enacted support because enacted support appears to have substantial portions of both trait and social influences, and these two influences appear to have different links to other constructs. In this final section, we discuss implications for social support theory and for understanding the links between enacted support and affect, address an apparent contradiction between the current findings and the findings of Bolger and colleagues (Bolger \& Amarel, 2007; Bolger et al., 2000; Gleason et al., 2008), and discuss more thoroughly the limitations of the current studies.

The current findings for social influences offer mixed support for stress and coping social support theory (Cutrona \& Russell, 1990; Thoits, 1986). On one hand, enacted support had the predicted links to low negative affect, positive affect, and perceived support. On the other hand, enacted support could not account for perceived support's links to favorable affect. Thus, perceived support's consistent and robust links to mental health still have not been explained completely in terms of enacted support; thus, alternative theoretical accounts are needed.

A comprehensive understanding of enacted support's link to affect will have to be able to account for both trait and social influences. Previous research has established that perceived support's link to mental health reflects both trait and social processes (Lakey \& Scoboria, 2005; Neely et al., 2006). The current studies are the first to document similar effects for enacted support. The operation of trait and social influences for enacted support and negative affect is especially interesting because here trait and social influences work in opposition. Thus, the mechanisms linking enacted support and negative affect likely differ for trait and social influences. For trait influences, recipients with the most chronic need (as reflected in negative affect) might elicit more support consistently across a range of providers (Barrera, 1986). Perhaps recognizing support receipt reflects badly on one's perceived efficacy, thus causing negative emotion (Barrera, 1986; Bolger \& Amarel, 2007). Trait negative affect is closely linked to neuroticism (Watson, Clark, McIntyre, \& Hamaker, 1992), and thus the mechanisms just described might partially reflect that broad personality trait. Yet part of the link between enacted support and low negative affect reflected social influences, as described by stress and coping social support theory (Cutrona \& Russell, 1990; Thoits, 1986). The theory predicts that this link occurs by buffering the effects of stress (Cohen \& Wills, 1985) through influencing appraisal and coping. Further research should test these hypotheses.

Consistent with previous research on perceived support (Lakey \& Scoboria, 2005; Neely et al., 2006) both the trait and socially influenced aspects of enacted support were linked to positive affect. Perceived support, enacted support, and positive affect were intercorrelated when the three reflected trait influences. This shared variance likely reflects trait extroversion given the intercorrelations previously observed among positive affect, extroversion, social activities, and support satisfaction (Finch, 1998; Watson et al., 1992). Thus, extroverts might receive greater enacted support simply as a by-product of their more frequent social interaction. For social influences, links among perceived support, enacted support, and positive affect might reflect 
network members' responses to positive events, as described by Gable et al. (2004). Network members' responses to positive events have been linked to greater positive affect and relationship satisfaction (Gable et al., 2004). At first glance, enacted support might not seem relevant to reactions to positive events, but many enacted support items could be interpreted by participants as referring to positive events, especially the positive social exchange subtype, which includes items such as "talked with you about some interests of yours" (Finch et al., 1997).

The link between enacted support and low negative affect when correlations reflected social influences appears to contradict the results of Bolger and colleagues. In daily diary studies (Bolger et al., 2000; Gleason et al., 2008), daily enacted support from partners was linked to increased daily negative affect. Because this phenomenon covaried over time and with social interaction, it was likely social in nature rather than a reflection of recipient trait influences, hence the contradiction with our current findings: We found a link between enacted support and low negative affect for one social influence whereas Bolger and colleagues found the opposite link for a similar social influence. One potentially important methodological difference between our studies and Bolger and colleagues' diary studies is that in the diary studies, each recipient described interactions with a single, specific other over multiple occasions. Thus, the diary studies isolated variation across days with the same provider, whereas our studies isolated variation across different providers. Thus, our research and Bolger and colleagues' research might simply be examining different social processes.

Another possibility is that the phenomenon identified by Bolger and colleagues reflected provider influences whereas our link between enacted support and low negative affect reflected relational influences. Recall that although provider and relational influences are distinct, the current studies confounded the two influences. Yet estimates of the size of relational and provider influences in fully crossed designs suggest that the largest share of social influences in our studies should be relational (Lakey, in press). Recall also that provider influences are defined in terms of interrater agreement. In some diary studies (Bolger et al., 2000), the link between enacted support and negative affect occurred when both recipients and providers agreed that support had been given. In experimental studies, Bolger and Amarel (2007) found the link between enacted support and negative affect when support provision was visible instead of invisible. When support was visible, nearly all recipients agreed that it had occurred. When support was invisible, almost no recipients agreed that it had occurred. Thus, the operationalization of visible support overlaps substantially with the operationalization of provider effects. Fully crossed designs that isolate recipient, provider, and relational influences could test our hypothesis that enacted support is linked to low negative affect for relational influences but to high negative affect for provider influences.

Before closing, we should discuss some of the limitations of the current studies. First, some readers might find our results more convincing if we had used behavioral observational measures. Although it would be worthwhile to conduct such studies, we used the self-report measure that yielded the countertheoretical findings for enacted support initially. Moreover, behavioral observational measures of enacted support typically show the same types of links to perceived support and mental health as do self-report measures (Collins \& Feeney, 2002; Lakey \& Heller, 1988). Second, because affect was assessed with regard to each relationship figure, assessments of support might have been confounded by affect. The current studies cannot rule out that possibility. Yet such an effect might reflect one of the key mechanisms by which support is linked to affect. Lakey and Drew (1997) hypothesized that support perceptions are derived, in part, from the affect that relationship figures typically elicit from support recipients and that much of this is derived from social interactions other than social support. The findings of the current studies were consistent with this interpretation. Third, it is not clear to what extent the findings from the current studies would generalize to social support measures that ask respondents to report on their social networks in general. Such general measures cannot distinguish between trait and social influences as defined by G and SRM approaches, and thus their estimates of links between social support and other constructs represent an unknown blend of trait and social influences. Finally, our findings might be specific to college students of predominantly European ancestry. Enacted support, especially from parents, might operate differently among college students, or among young adults more generally, than among people at other stages of life. Social support also might operate differently in cultures not derived from European cultures. Additional studies are needed to assess the generality of the current findings.

In conclusion, when correlations reflected social influences, enacted support was linked to low negative affect and high positive affect, and strongly linked to perceived support as predicted by stress and coping social support theory. When correlations reflected recipient trait influences, enacted support's links were mostly contrary to stress and coping social support theory: Receiving enacted support was linked to more, rather than less, negative affect and enacted support was weakly and inconsistently linked to perceived support. Nonetheless, enacted support could explain only a small portion of perceived support's link to affect when correlations reflected social influences. Thus, additional theoretical development is needed to explain perceived support's link to mental health.

\section{Authors' Note}

Meredith VanVleet is now at Carnegie Mellon University. 


\section{Acknowledgments}

Arika Cronin, Kate Hellman, and Amy Veenstra provided valuable assistance in preparing the data for Study 1.

\section{Declaration of Conflict of Interests}

The authors declared that they had no conflicts of interests with respect to their authorship or the publication of this article.

\section{Funding}

The authors declared that they received the following financial support for their research on this article: Grand Valley State University and the University of Maryland.

\section{Notes}

1. Internal consistency reliability formulas were $\alpha_{r}=\sigma_{r}^{2} /\left[\left(\sigma_{r}^{2}+\right.\right.$ $\left.\left(\sigma_{r x i}^{2} / n_{i}\right)\right]$ for recipient trait influences and $\alpha_{s}=\sigma_{p \text { nested within } r}^{2}$ $\left[\left(\sigma_{p \text { nested within } r}^{2}+\left(\sigma_{p \text { nested within } r x i}^{2} / n_{i}\right)\right]\right.$ for social influences, in which $r$ indicates recipients, $p$ indicates providers, $i$ indicates items, and $n_{i}$ indicates number of items.

2. With the occasional exception of tangible support, the pattern of findings in both studies was replicated for the subscales as well. Subscale findings are available from the authors.

3. In calculating standardized residuals we treated each recipientprovider dyad as a case.

4. Some readers might wonder why we did not analyze the data as a short-term prospective design in which Time 1 support forecasted changes in affect from Time 1 to Time 2. Although the data could be analyzed in such a way, the study was not designed for that purpose and has features that make it a suboptimal prospective study. For example, the lag between the two time points was very brief ( 2 weeks) and the time frames for which respondents were asked to report overlapped between the two assessment points. For example, participants reported enacted support over the past month and so enacted support reported for Time 2 overlapped with the time frame for reporting enacted support at Time 1.

\section{References}

Barrera, M., Jr. (1986). Distinctions between social support concepts, measures, and models. American Journal of Community Psychology, 14, 413-455.

Barrera, M., Sandler, I. N., \& Ramsay, T. B. (1981). Preliminary development of a scale of social support: Studies on college students. American Journal of Community Psychology, 9, 435-447.

Barry, R., Lakey, B., \& Orehek, E. (2007). Links among attachment dimensions, affect and the self for broadly-generalized attachment styles and relationship-specific bonds. Personality and Social Psychology Bulletin, 33, 240-253.

Bolger, N., \& Amarel, D. (2007). Effects of social support visibility on adjustment to stress: Experimental evidence. Journal of Personality and Social Psychology, 92, 458-475.

Bolger, N., Zuckerman, A., \& Kessler, R. C. (2000). Invisible support and adjustment to stress. Journal of Personality \& Social Psychology, 79, 953-961.
Brennan, R. L. (2001a). Generalizability theory. New York: Springer.

Brennan, R. L. (2001b). Manual for mGENOVA, Version 2.1 (Occasional Paper No. 50). Iowa City: Iowa Testing Programs.

Brewin, C. R., Andrews, B., \& Valentine, J. D. (2000). Metaanalysis of risk factors for posttraumatic stress disorder in trauma-exposed adults. Journal of Consulting and Clinical Psychology, 68, 748-766.

Campbell, L., Simpson, J. A., Boldry, J., \& Kashy, D. A. (2005). Perceptions of conflict and support in romantic relationships: The role of attachment anxiety. Journal of Personality and Social Psychology, 88, 510-531.

Cohen, S., \& Hoberman, H. M. (1983). Positive events and social supports as buffers of life change stress. Journal of Applied Social Psychology, 13, 99-125.

Cohen, S., \& Wills, T. A. (1985). Stress, social support, and the buffering hypothesis. Psychological Bulletin, 98, 310-357.

Collins, N. L., \& Feeney, B. C. (2002). A safe haven: An attachment theory perspective on support seeking and caregiving in intimate relationships. Journal of Personality and Social Psychology, 78, 1053-1073.

Cronbach, L. J., Gleser, G. C., Nanda, H., \& Rajaratnam, N. (1972). The dependability of behavioral measurements:Theory of generalizability of scores and profiles. New York: John Wiley.

Cutrona, C. E., \& Russell, D. W. (1990). Type of social support and specific stress: Toward a theory of optimal matching. In B. R. Sarason, I. G. Sarason, \& G. R. Pierce (Eds.), Social support: An interactional view (pp. 319-366). New York: John Wiley.

Eastwick, P. W., Finkel, E. J., Mochon, D., \& Ariely, D. (2008). Selective versus unselective romantic desire: Not all reciprocity is created equal. Psychological Science, 18, 317-319.

Finch, J. F. (1998). Social undermining, support satisfaction, and affect: A domain-specific lagged effects model. Journal of Personality, 66, 315-334.

Finch, J. F., Barrera, M., Jr., Okun, M. A., Bryant, W. H. M., Pool, G. J., \& Snow-Turek, L. (1997). The factor structure of received social support: Dimensionality and the prediction of depression and life satisfaction. Journal of Social and Clinical Psychology, 16, 323-342.

Finch, J. F., Okun, M. A., Pool, G. J., \& Ruehlman, L. S. (1999). A comparison of the influence of conflictual and supportive social interactions on psychological distress. Journal of Personality, 67, 581-621.

Gable, S. L., Reis, H. T., Impett, E. A., \& Asher, E. R. (2004). What do you do when things go right? The intrapersonal and interpersonal benefits of sharing positive events. Journal of Personality and Social Psychology, 87, 228-245.

Gleason, M. E. J., Iida, M., Shrout, P. E., \& Bolger, N. (2008). Receiving support as a mixed blessing: Evidence for dual effects of support on psychological outcomes. Journal of Personality and Social Psychology, 94, 824-838.

Haber, M. G., Cohen, J. L., Lucas, T., \& Baltes, B. B. (2007). The relationship between self-reported received and perceived social support: A meta-analytic review. American Journal of Community Psychology, 39, 133-144. 
Kenny, D. (1994). Interpersonal perception: A social relations analysis. New York: Guilford.

Kenny, D. A., \& Winquist, L. A. (2001). The measurement of interpersonal sensitivity: Consideration of design, components, and unit of analysis. In J. A. Hall \& F. J. Bernieri (Eds.), Interpersonal sensitivity: Theory and measurement (pp. 265-302). Mahwah, NJ: Lawrence Erlbaum.

Kwan, V. S. Y., John, O. P., Kenny, D. A., Bond, M. H., \& Robins, R. W. (2004). Reconceptualizing individual differences in selfenhancement bias: An interpersonal approach. Psychological Review, 111, 94-110.

Lakey, B. (in press). Social-clinical approaches to social support suggest new strategies for intervention. In J. E. Maddux \& J. P. Tangney (Eds.), Social psychological foundations of clinical psychology. New York: Guilford.

Lakey, B., \& Cohen, S. (2000). Social support theory and selecting measures of social support. In S. Cohen, L. U. Gordon, \& B. H. Gottlieb (Eds.), Social support measurement and interventions: A guide for health and social scientists (pp. 29-52). New York: Oxford University Press.

Lakey, B., \& Cronin A. (2008). Low social support and major depression: Research, theory and methodological issues. In K. S. Dobson \& D. Dozois (Eds.), Risk factors for depression (pp. 385-408). San Diego, CA: Academic Press.

Lakey, B., \& Drew, J. B. (1997). A social-cognitive perspective of social support. In G. R. Pierce, B. Lakey, I. G. Sarason, \& B. R. Sarason (Eds.), Sourcebook of social support and personality (pp. 107-140). New York: Plenum.

Lakey, B., \& Heller, K. (1988). Social support from a friend, perceived support and social problem solving. American Journal of Community Psychology, 16, 811-825.

Lakey, B., \& Scoboria, A. (2005). Trait and social influences in the links between perceived social support and mental health. Journal of Personality, 73, 361-388.

Lemay, E. P., Jr., \& Clark, M. S. (2008). How the head liberates the heart: Projection of communal responsiveness guides relationship promotion. Journal of Personality and Social Psychology, 94, 647-671.

Merlo, L., \& Lakey, B. (2007). Trait and social influences in the links among adolescent attachment, coping, and depressive symptoms. Journal of Clinical Child and Adolescent Psychology, 36, 195-206.

Mooney, C. Z., \& Duval, R. D. (1993). Bootstrapping: A nonparametric approach to statistical inference. Newbury Park, CA: Sage.
Neely, L. C., Lakey, B., Cohen, J. L., Barry, R., Orehek, E., Abeare, C. A., et al. (2006). Trait and social processes in the link between social support and affect: An experimental laboratory investigation. Journal of Personality, 74, 1015-1046.

Penley, J. A., Tomaka, J., \& Wiebe, J. S. (2002). The association of coping to physical and psychological health outcomes: A metaanalytic review. Journal of Behavioral Medicine, 25, 551-603.

Pierce, G. R., Sarason, I. G., \& Sarason, B. R. (1991). General and relationship-based perceptions of social support: Are two constructs better than one? Journal of Personality and Social Psychology, 61, 1023-1039.

Rini, C., Dunkel Schetter, C., Hobel, C. J., Glynn, L. M., \& Sandman, C. A. (2006). Effective social support: Antecedents and consequences of partner support during pregnancy. Personal Relationships, 13, 207-229.

Seidman, G., Shrout, P. E., \& Bolger, N. (2006). Why is enacted social support associated with increased distress? Using simulation to test two possible sources of spuriousness. Personality and Social Psychology Bulletin, 32, 52-65.

StataCorp. (2003). Stata statistical software (Release 8) [Computer software and manual]. College Station, TX: Stata Press.

Stice, E. (2002). Risk and maintenance factors for eating pathology: A meta-analytic review. Psychological Bulletin, 128, 825-848.

Strube, M. J. (2000). Reliability and generalizability theory. In G. G. Laurence \& P. R. Yarnold (Eds.), Reading and understanding MORE multivariate statistics (pp. 23-66). Washington, DC: American Psychological Association.

Thoits, P. A. (1986). Social support as coping assistance. Journal of Consulting and Clinical Psychology, 54, 416-423.

Watson, D., Clark, L. A., \& Carey, G. (1988). Positive and negative affectivity and their relation to anxiety and depressive disorders. Journal of Abnormal Psychology, 97, 346-353.

Watson, D., Clark, L. A., McIntyre, C. W., \& Hamaker, S. (1992). Affect, personality, and social activity. Journal of Personality and Social Psychology, 63, 1011-1025.

Watson, D., Clark, L. A., \& Tellegen, A. (1988). Development and validation of brief measures of positive and negative affect: The PANAS scales. Journal of Personality and Social Psychology, 54, 1063-1070.

Wills, T. A., \& Shinar, O. (2000). Measuring perceived and received social support. In S. Cohen, L. G. Underwood, \& B. H. Gottlieb (Eds.), Social support measurement and intervention (pp. 86-135). New York: Oxford University Press. 